\title{
Risk Assessment of Factors Related to Fire Protection in Dwellings
}

\author{
JEREMY FRASER-MITCHELL \\ Fire Research Station \\ Building Research Establishment, UK
}

\begin{abstract}
A Monte Carlo simulation (CRISP) of entire fire scenarios has been developed for use in risk assessment. CRISP's basic structure is a two layer multi-room zone model, with extra features, most notably people, included. The model has been used to perform a fire risk assessment of a domestic house. If a house has more than two storeys (which may also be the case if an attic or roof space has been converted for use as living accommodation in a two-storey house), the Approved Document of the Building regulations for England and Wales recommends protecting the staircases with fire-resisting construction. The purpose of the CRISP study was to investigate whether the provision of smoke alarms would remove the need for staircase protection. It was found that smoke alarms did provide an acceptable level of risk for the occupants, which was comparable to that provided by passive fire protection.
\end{abstract}

KEYWORDS: $\quad$ Risk Assessment, Monte Carlo simulation, domestic house.

\section{INTRODUCTION}

In essence, the Building Regulations for England and Wales only require a building to be 'reasonably safe' in the event of fire. Following the procedures specified in the Approved Document [1] is deemed to be one way of satisfying this requirement. However, using the Approved Document as a prescriptive requirement may place an unnecessary financial burden on the builder, or in some cases may not permit a building design at all. There is a clear need for tools which can compare fire risks associated with different designs.

The Fire Research Station is developing such a tool, called CRISP (Computation of Risk Indices by Simulation Procedures). It is a Monte Carlo simulation of entire fire scenarios. The behaviours of the submodels are described more fully in a previous paper [2], but are outlined here for completeness. All component sub-models run simultaneously, and interact with one-another. The sub-models representing physical 'objects' include rooms, doors, windows, detectors, items of furniture, etc, hot smoke layers and people. The stochastic aspects include starting conditions such as windows and doors open or closed, the number, type and location of people in the building, the location of the fire and the type of burning item. 
The first application of the model has been a fire risk assessment of a domestic house. If the house has more than two storeys, Approved Document B advises that the staircases (ie. the escape routes) should be protected with fire-resisting construction to separate it from other rooms. This advice also covers cases where an attic or roof space has been converted into living accommodation, thus transforming a twostorey house into three storeys. The purpose of the CRISP study was to investigate whether the provision of smoke alarms would remove the need for special passive fire protection measures.

CRISP does not explicitly model fire resistance, all barriers are assumed to retain their integrity for the duration of the simulation. The great majority of scenarios are resolved in less than 10 minutes, so this assumption may not be too bad. It is also assumed there is no smoke spread through cavities. However, doors can be specified as self-closing.

The analysis has been restricted to flaming fires on single items. Smouldering fires are unlikely to affect people outside the room of origin, so the effect of passive protection or alarms would be limited. CRISP does not model the spread of fire beyond the first item, so it has only been possible to estimate the upper limit of the effect of flashover scenarios.

When using risk-based design methods, there is a fundamental question of how safe the design should be, since 'totally safe' is unachievable. In the absence of a generally accepted absolute level, the normal approach is to aim for a design that achieves at least an equivalent level of safety as a similar design satisfying prescriptive regulations. In the domestic case studied here there are two possibilities, the protected staircase as required for a three-storey building, or an ordinary two-storey house without any special measures. The relative risk for the occupants on the upper storey compared to those below may suggest which option is appropriate.

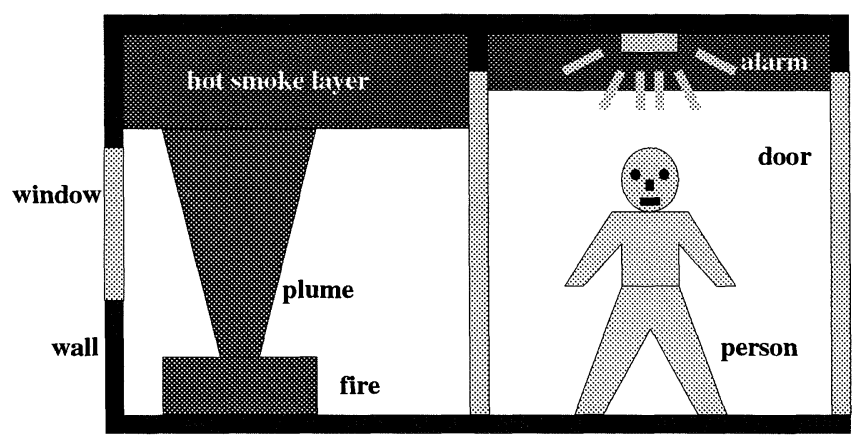

FIGURE 1. The main physical 'objects' represented in the CRISP model

\section{THE CRISP MODEL}

The basic structure of CRISP is a two-layer zone model for multiple rooms. The principal physical 'objects' included in the model (figure 1) are the fire, hot smoke layers, rooms, doors and windows, alarms, and people. The calculations are carried out iteratively, with variable time intervals. Execution time is typically 20 seconds per scenario, running on a Macintosh Quadra 700. 
The detection process checks if the optical density of the smoke layer in the room containing the alarm exceeds a threshold value of $0.1 \mathrm{~m}^{-1}[3]$ (where light intensity falls by $\mathrm{I}=\mathrm{I}_{0} .10^{-\mathrm{oD} . \mathrm{d}} ; \mathrm{d}=$ path length). A simple algorithm for noise attenuation is included, to see if the alarm is heard by people in other rooms.

\section{$\underline{\text { Fire }}$}

The combustion process assumes that flames spread radially at a constant rate across a horizontal surface. Other configurations are accounted for by modifying the variable parameters. The radiant heat flux from the flames [4] and hot smoke layer determines the pyrolysis rate per unit area [5]. Oxygen entrained into the plume [6,7] from both the cold and hot [8] gas layers affects the combustion efficiency [5,9], and hence the heat output rate to be used in the next iteration. The initial conditions are a heat release rate of $1 \mathrm{~kW}$, and a fire radius chosen to give zero flame height [10]. The burning item parameters are all variables which may be adjusted to reproduce experimental observations [11,12]. Predicted heat release rates for items burning in fully ventilated conditions give satisfactory agreement.

\section{Gas Layers}

Combustion products are transported between the various layers by plumes and vent flows. Heat may also be lost by radiation and conduction [13] through the walls of the compartment. The buoyancy of the hot and cold layers determines whether plumes and vent flows rise or sink.

\section{Humans}

People firstly gather information about the fire, the tenability of the rooms, and the status and actions of other people. They then make deterministic decisions on the basis of their knowledge. The actions which they may perform $[2,14]$ depend on their behaviour class, and include investigating, fire fighting, warning, rescuing, escaping, etc. Some actions require the person to move to another room, so route planning must take room tenabilities into account. Movement is simply from room centre to door to room centre,etc. Obstructions and constrictions are ignored for the domestic case, since they are unlikely to have a significant effect. The toxicological effects [15] of the gas layer at a person's head height are expressed in terms of fractional effective dose (FED). When FED $=1$, the person becomes unconscious.

\section{$\underline{\text { Rooms }}$}

The geometry of the room determines how quickly a growing smoke layer will descend. The tenability of the room $[2,15]$ is a measure of the psychological effects of radiant and convective heat, smoke obscuration and breathing difficulty.

\section{Vents}

Vents are doors and windows. Opening and closing during the simulation occurs when people move through. The traversal difficulty includes physical and psychological aspects [2]. Smoke moves between rooms by means of vent flows [16], driven by pressures arising from buoyancy differences. These flows form vent plumes [17], which may cause further mixing of the gas layers in the room they flow into.

\section{Supporting code}

All the physical 'objects' are supervised by the Monte Carlo controller, making each one perform for each timestep. The Monte Carlo controller also handles all the input and output, initialisation for each run, and starts each run automatically. Functions are included to generate random numbers from any distribution. The program's efficiency, accuracy and stability is governed by the timestep controller. Routines for post-processing of output data are provided; others were added to look more deeply at interesting results.

\section{SIMULATION OF A DOMESTIC HOUSE}

As mentioned in the introduction, if the house has more than two storeys the UK Building Regulations 
suggest the staircases should be protected with fire-resisting construction to separate them from other rooms. The objective of the CRISP simulations was to investigate whether provision of smoke alarms could achieve an equivalent level of safety, and hence remove the need for this passive protection.

The floorplan of a 'typical' 3 bedroomed house with loft conversion is shown in figure 2; the size of the ground floor is $6 \mathrm{~m} \times 7 \mathrm{~m}$. It is based closely (but not precisely) on the experimental house built in BRE's Cardington Laboratory. To preserve the similarity, attic access is by a 'trapdoor' rather than a staircase, however this does not significantly affect evacuation time, etc.

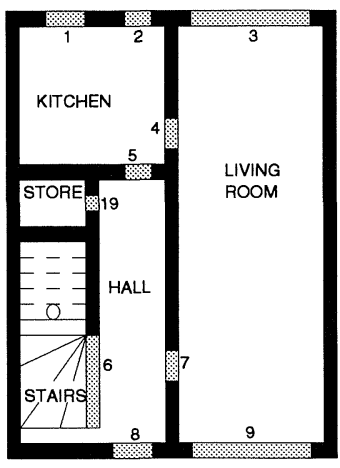

Ground Floor

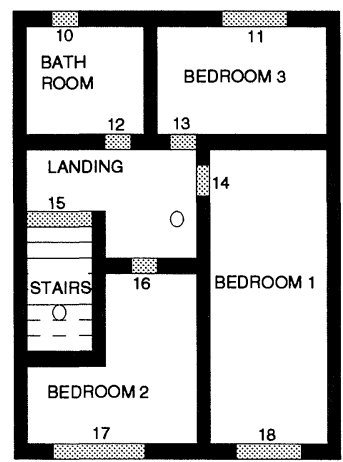

First Floor

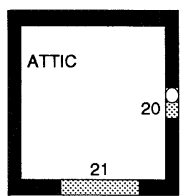

Second Floor

FIGURE 2. The floor plan of the typical 3-bedroomed house with attic / loft conversion The rooms are named, and the vents numbered by their id no. (The small circles show the points where people move from one floor to another)

The starting point of each run in the simulation is to determine the fire scenario, defined by the season of the year, the time of day, the room type and the item type. The probabilities for each scenario have been derived from Home Office statistics [18]. The actual room of origin and item ignited are chosen randomly with equal weight, from lists of what is available of the chosen type. Other important parameters which depend on the time of day, and to a lesser extent the season, are the probability of doors and windows being open [19], the external air temperature, and the location of the people.

The basic family type is randomly chosen from a list of the most common combinations, derived from census figures [20]. Relative probabilities of the family types in 3-bedroom houses (table 1) were derived from the statistics for all dwellings. The chief assumption was that larger houses were occupied by larger families (ie. the 'bedroom standard' [20] was a constant). There is a $4 \%$ probability for a married couple (family types 13-16) to share with another family unit, and a $14 \%$ chance for a single mother (family types 10-12) to do so. The second family unit (if required) was chosen from types 1-5. This defines the numbers of adults, children, elderly, etc, which are not independent. Depending on the time of day, people may be absent from the house, asleep in their own bedroom, or awake in various rooms. The rules for bedroom assignment are an extension of those used to define 'bedroom standard'.

The relative effectiveness of doors and alarms was examined by 16 cases ( 4 door options $\mathrm{x} 4$ alarm options). In all cases the external doors and windows were all closed. The internal door options are: all open, all closed, normal use (mixture of open and closed, the probability of being shut is given in table 2 ), all self-closing. Vents 6 and 15 are archways rather than doors, so open all the time. The alarm options were no detectors, one detector in the landing, two detectors (landing and hall), and detectors in all rooms. 
Reliability of alarms, or the chance of self-closing doors being wedged open, have not been considered explicitly in the model. The importance of these factors can be deduced by considering combinations of different cases, eg. a single detector that failed to activate is no different from a case where the detector was not present.

TABLE 1. The probabilities of various family types occupying a 3-bedroomed house

\begin{tabular}{|l|l|l|}
\hline ID & Family Profile & Probability \\
\hline 01 & 1 adult & 0.016 \\
02 & 1 elderly & 0.038 \\
03 & 1 adult, 1 elderly & 0.118 \\
04 & 2 elderly & 0.021 \\
05 & 2 adults & 0.039 \\
06 & 3 adults & 0.078 \\
07 & 4 adults & 0.111 \\
08 & 5 adults & 0.028 \\
\hline
\end{tabular}

\begin{tabular}{|r|l|l|}
\hline ID & Family Profile & Probability \\
\hline 09 & 6 adults & 0.007 \\
10 & 1 adult, 1 child & 0.019 \\
11 & 1 adult, 2 child & 0.021 \\
12 & 1 adult, 3 child & 0.019 \\
13 & 2 adults, 1 child & 0.159 \\
14 & 2 adults, 2 child & 0.202 \\
15 & 2 adults, 3 child & 0.101 \\
16 & 2 adults, 4 child & 0.020 \\
\hline
\end{tabular}

TABLE 2. The probabilities of selected doors being shut during the day and night. Other doors and windows are always shut.

\begin{tabular}{|l|l|l|l|l|l|l|l|l|l|l|}
\hline Vent ID (see floor plan) & 04 & 05 & 06 & 07 & 12 & 13 & 14 & 15 & 16 & 20 \\
\hline $\operatorname{pr}$ (shut I daytime ) & 0.1 & 0.2 & 0.0 & 0.2 & 0.9 & 0.3 & 0.3 & 0.0 & 0.3 & 1.0 \\
$\operatorname{pr}$ (shut I nighttime ) & 0.4 & 0.4 & 0.0 & 0.4 & 0.9 & 0.5 & 0.5 & 0.0 & 0.5 & 0.0 \\
\hline
\end{tabular}

\section{RESULTS}

\section{Basic Risk Calculations}

The risk of death is defined as the total number of occupants over all the runs whose FED exceeds $100 \%$, divided by the total number initially at risk. Similarly the risk of injury has been defined as the percentage of occupants whose FED is in the range $10-100 \%$. It is worth stressing at this stage that, where errors are quoted in the following tables, these refer only to the standard deviations (on the mean) of the output and are not estimates of the inaccuracies of the assumptions in the model and its data.

Examining the risk of death in the 16 cases (table 3 ) we see that, with no detectors, it is clearly beneficial for the doors to be shut. With doors in normal use or always open, adding detectors led to a clear reduction in risk. This was all as expected, however what was not expected was that adding detectors to a house where the doors were kept closed would increase the risk! A possible explanation for this is that when people are alerted someone goes to investigate the fire, then other people are warned / rescued before escape. During this time the doors will be left open unless the smoke is perceived as a threat, without being so severe as to prevent the door being shut. Note that the risk level for ordinary doors kept closed rises to values which are very similar to those for doors originally open, whereas with selfclosing doors the risk is lower. 
The highest risk of injury (table 4) is for doors in normal use or always open, and no detectors present. Adding detectors to these cases reduces the risk. However, with doors closed detectors make very little difference. Note also the risk of injury is higher when doors are closed, compared to doors open, when detectors are present. An explanation for this is that the room fills with smoke more quickly, so people are more likely to receive a significant dose before they can escape.

Based purely on these results, the advice would be to fit self-closing doors and no detectors. However, the sensitivity of the model to the assumptions in the algorithms and the data is not known for all cases, so it is prudent to make a more detailed examination of the results.

TABLE 3. The risk of death, for four cases of door usage and four cases of smoke detector provision. The errors are one standard deviation of the error on the mean.

\begin{tabular}{|c|c|c|c|c|c|}
\hline & & \multicolumn{4}{|c|}{ DETECTORS } \\
\hline & & none & one & two & all \\
\hline D & self-closing & $1.4 \pm 0.2$ & $1.9 \pm 0.2$ & $2.0 \pm 0.1$ & $2.0 \pm 0.1$ \\
\hline $\begin{array}{l}\mathrm{O} \\
\mathrm{O}\end{array}$ & all closed & $1.8 \pm 0.1$ & $2.6 \pm 0.1$ & $3.0 \pm 0.1$ & $3.0 \pm 0.1$ \\
\hline $\mathrm{R}$ & normal use & $7.6 \pm 0.1$ & $3.3 \pm 0.1$ & $2.8 \pm 0.1$ & $2.8 \pm 0.1$ \\
\hline $\mathrm{S}$ & all open & $8.9 \pm 0.1$ & $2.3 \pm 0.1$ & $2.6 \pm 0.1$ & $2.8 \pm 0.1$ \\
\hline
\end{tabular}

TABLE 4. The risk of 'injury' (ie. fractional effective dose of 10-99\%), for four cases of door usage and four cases of detector provision. The errors are one standard deviation of the error on the mean.

\begin{tabular}{|l|l|l|l|l|l|}
\cline { 3 - 6 } \multicolumn{2}{c|}{} & \multicolumn{4}{|c|}{ DETECTORS } \\
\cline { 2 - 6 } \multicolumn{2}{c|}{} & none & one & two & all \\
\hline $\mathrm{D}$ & self-closing & $5.4 \pm 0.1$ & $4.9 \pm 0.1$ & $5.1 \pm 0.1$ & $5.2 \pm 0.1$ \\
$\mathrm{O}$ & all closed & $6.2 \pm 0.1$ & $5.2 \pm 0.1$ & $5.9 \pm 0.1$ & $4.8 \pm 0.1$ \\
$\mathrm{R}$ & normal use & $9.5 \pm 0.1$ & $3.6 \pm 0.1$ & $3.2 \pm 0.1$ & $3.1 \pm 0.1$ \\
$\mathrm{~S}$ & all open & $8.0 \pm 0.1$ & $2.3 \pm 0.1$ & $1.8 \pm 0.1$ & $1.8 \pm 0.1$ \\
\hline
\end{tabular}

\section{Effect of Dependents}

In the domestic case, the behavioural model for the people is either 'leader', 'led', or 'dependent' [2]. The behavioural rules for the dependents do not allow them to escape unaided, thus the numbers of dependent persons present has a significant impact on the risk or death. Firstly note from table 5 that the total numbers of dependents is quite high (mainly due to young children). Also, since the program assigns each person's location independently, quite a large proportion of the population consists of dependents who have been left 'home alone'.

The relative risk of any member of the family dying is significantly increased when dependents comprise more than half of the family present. This is because at least one of the rescuers will have to re-enter the building if everyone is to be saved. With all of the inhabitants dependent, the risk is higher still, since they 
simply wait for help which does not come. In these 'home alone' cases one might expect the risk of death to be much higher, $\sim 100 \%$, but the reason why it is not lies in the limitations of the model. Firstly, the fire does not spread beyond the item first ignited; secondly, the hot smoke layer never mixes with clear air in the same room (except by ventplume entrainment), even when it has cooled to the same temperature. The people can sit around indefinitely with the smoke layer above their heads.

TABLE 5. The effect of the proportion of dependents among the people present during the fire. The population fraction is the percentage of all the occupants, summed over all the runs, who were in a family with the given proportion of dependents. The risk of death (also calculated from all runs, even though cases such as 'doors open, no detectors' are very different to others) is the probability that a person in the given family type (dependent fraction) will acquire a fractional dose of $100 \%$ or more.

\begin{tabular}{|l|c|c|c|c|}
\hline Family's dependent fraction present & none & $<$ half & $>$ half & all \\
\hline Population fraction in such a family $(\%)$ & 60 & 17 & 15 & 8 \\
\hline Risk of death in such a family (\%) & 1.8 & 2.2 & 4.5 & 9.0 \\
\hline
\end{tabular}

\section{Contributions to the risk}

The contributions from home alone, unalert and various categories of alerted fatalities are shown in table 6. It was found that the differences between the four different door options could be explained primarily by whether the room containing the fire has all its doors closed or not. The 'home alone' deaths have already been discussed. It may be acceptable to ignore these deaths, since they may be a consequence of the way the model populates the building, rather than being real.

Without detectors, unalert deaths are the commonest, and the dominant cause when doors are open. As soon as detectors are fitted, this component becomes negligible for all cases.

Alerted people who nevertheless die have been sorted into 3 categories: immobile, overtaken or trapped, depending on the time it would have taken then to leave the building if they had started to escape at once on being alert, compared with the time after alert when they were overcome. The time to leave the house is very short $(\sim 15-20 \mathrm{sec})$ for able-bodied people, so the 'trapped' component is much larger than the 'overtaken'. It is possible that a number of the 'trapped' deaths may have been saved if the people had run through the smoke regardless of its apparent tenability.

'Overtaken' deaths are quite serious when doors are closed, this is presumably due to people only becoming alert when the fire is already quite large (especially if they are in the fire room itself). However this component is negligible when the doors are open, since the smoke is more dilute, and people can see it before they are exposed to it. 'Immobile' deaths are unaffected by the state of the fire room's doors, so there must be a number of counterbalancing effects. For example, when the fire room is closed there would be more deaths there but less in other rooms. 'Trapped' deaths are slightly higher for closed rooms rather than open. In this case it is likely that other doors within the house are closed as well, thus concentrating the smoke to block the escape route.

Based on these results, detectors are clearly desirable, and having two is almost as good as having one for every room. Having the doors open is predicted as being slightly better than having them closed, but in view of the model's limitations it might be more advisable to rely on 'common sense' and recommend that they be closed. Self closing doors are not necessary, their benefits would be marginal. 
TABLE 6. Contributions to the \% risk of death, as a result of various causes. It was noted that the differences between the 4 cases of door usage could mainly be explained by whether or not the room of fire origin had all its doors closed, or whether one or more were open.

\begin{tabular}{|c|c|c|c|c|c|c|c|c|c|}
\hline \multirow{2}{*}{\multicolumn{2}{|c|}{ pical }} & \multicolumn{4}{|c|}{$\begin{array}{l}\text { FIRE ROOM 'CLOSED': } \\
\text { DETECTORS }\end{array}$} & \multicolumn{4}{|c|}{$\begin{array}{l}\text { FIRE ROOM 'OPEN': } \\
\text { DETECTORS }\end{array}$} \\
\hline & & none & one & two & all & none & one & two & all \\
\hline \multirow{5}{*}{$\begin{array}{l}\text { DEATH } \\
\text { TYPE }\end{array}$} & home alone & 0.5 & 0.3 & 0.5 & 0.4 & 1.1 & 1.2 & 1.1 & 0.9 \\
\hline & not alerted & 0.8 & 0.1 & 0.1 & 0.1 & 5.0 & 0.0 & 0.0 & 0.0 \\
\hline & immobile & 0.5 & 0.8 & 0.4 & 0.3 & 0.5 & 0.4 & 0.4 & 0.3 \\
\hline & overtaken & 0.5 & 0.5 & 0.3 & 0.0 & 0.1 & 0.1 & 0.0 & 0.0 \\
\hline & trapped & 0.5 & 0.9 & 1.0 & 0.7 & 0.5 & 0.7 & 0.4 & 0.3 \\
\hline
\end{tabular}

\section{Third Storey - a special case?}

In the domestic case we are studying, the key question is whether the occupants of the attic / loft conversion have a higher risk of death than the occupants of the other bedrooms. If they do, the risk of death associated with the chosen design must be no higher than that associated with \{ self closing doors + no detectors\} (treating the Approved Document's recommendation as a prescription). On the other hand, if the risk for the attic / loft is not significantly higher than other rooms, the chosen design only has to out-perform a normal two-storey house for which no special measures are suggested (ie. \{'normal' doors + no detectors $\}$ ). This latter case is not a particularly challenging one to beat!

The initial analysis revealed that number of deaths occurring in the attic forms a tiny fraction ( $5 \%)$ of the whole (especially with detectors, since the attic occupants are able-bodied and can escape if warned). The program does not populate the attic very often, but in any case the relative risk of death on the top floor does not seem to be any higher than the other bedrooms. The number of deaths were very small and thus subject to large fractional error. More runs have been performed where the scenario is only simulated if the attic is initially occupied. (Variance reduction by Importance Sampling - see later). Further variance reduction was achieved be exploiting a correlation [21] between the risk of death and the Fractional Effective Dose averaged over all the occupants. The results are shown in tables 7A and 7B.

TABLE 7A. The average Fractional Effective Dose (FED) for occupants of the first floor bedrooms, for four cases of door usage and four cases of smoke detector provision The errors are one standard deviation of the error on the mean. (Risk of death is correlated with average FED)

\begin{tabular}{|c|c|c|c|c|c|}
\hline & \multicolumn{4}{|c|}{ DETECTORS } \\
\hline & & none & one & two & all \\
\hline D & self-closing & $6.7 \pm 0.3$ & $4.0 \pm 0.3$ & $2.8 \pm 0.2$ & $1.5 \pm 0.2$ \\
\hline O & all closed & $5.8 \pm 0.3$ & $2.2 \pm 0.2$ & $2.2 \pm 0.2$ & $1.1 \pm 0.2$ \\
\hline $\mathrm{R}$ & normal use & $13.1 \pm 0.5$ & $2.7 \pm 0.2$ & $1.4 \pm 0.2$ & $0.8 \pm 0.1$ \\
\hline$S$ & all open & $7.1 \pm 0.4$ & $2.8 \pm 0.2$ & $1.5 \pm 0.2$ & $1.1 \pm 0.2$ \\
\hline
\end{tabular}


TABLE 7B. The average Fractional Effective Dose (FED) for occupants of the attic / loft conversion, for four cases of door usage and four cases of smoke detector provision The errors are one standard deviation of the error on the mean. Compare with the results in Table 7A.

\begin{tabular}{|c|c|c|c|c|c|}
\hline & & \multicolumn{4}{|c|}{ DETECTORS } \\
\hline & & none & one & two & all \\
\hline \multirow{4}{*}{$\begin{array}{l}\mathrm{D} \\
\mathrm{O} \\
\mathrm{O} \\
\mathrm{R} \\
\mathrm{S}\end{array}$} & self-closing & $6.3 \pm 0.5$ & $1.7 \pm 0.3$ & $1.4 \pm 0.3$ & $0.9 \pm 0.2$ \\
\hline & all closed & $5.0 \pm 0.5$ & $1.6 \pm 0.3$ & $0.8 \pm 0.2$ & $1.4 \pm 0.3$ \\
\hline & normal use & $11.2 \pm 0.8$ & $1.3 \pm 0.2$ & $0.9 \pm 0.2$ & $0.9 \pm 0.2$ \\
\hline & all open & $8.6 \pm 0.8$ & $3.3 \pm 0.5$ & $2.3 \pm 0.4$ & $1.4 \pm 0.3$ \\
\hline
\end{tabular}

These results show that active protection by detectors seems perfectly acceptable. The risk with detectors present is less than either of the two cases we might wish to demonstrate equivalency against. As the attic does not appear significantly more dangerous than the other bedrooms, the Approved Document recommendations do not result in a consistent level of safety.

\section{Flashover}

One of the limitations of the model is that it does not consider fire spread from one item to another; instead the fire is confined to the first item, and goes out when that runs out of fuel. In reality, fire may spread over continuous flammable surfaces and if the temperature of the hot layer reaches $550-600^{\circ} \mathrm{C}$, the radiant heat flux at floor level would be about $20 \mathrm{~kW} \mathrm{~m}^{-2}$, which would cause significant pyrolysis and / or ignition of other items - 'flashover' would occur.

It was found that about 7\% of all the fires simulated got hot enough for flashover. Note that this percentage is independent of the door closure probabilities. When the door is closed, heat is retained more effectively within the fire compartment, but the fire is starved of oxygen and cannot achieve flashover. (This may change if someone opens the door!). This value of $7 \%$ gives an upper limit to the risk of death from flashover, assuming no-one has left the building before flashover occurs, and none are able to survive once it has.

Research in the experimental house at Cardington has suggested that fires are very likely to selfextinguish when the doors and windows are closed [22]. When this happens, the structure does not need to have an extended period of fire resistance.

\section{Variance Reduction}

All Monte Carlo runs give uncertain results. The simplest way to reduce this uncertainty is to increase the number of runs. By the Central Limit Theorem, the error on the mean risk is inversely proportional to the square root of the number of runs performed.

Variance reduction techniques are employed to achieve greater accuracy more efficiently. The efficiency is the ratio of the time taken to achieve a certain accuracy, compared to the time required to achieve that accuracy simply by increasing the number of runs. 
In an earlier publication [2] it was suggested that variance reduction could be achieved by exploiting a correlation between the number of injuries and the number of deaths, assuming such a correlation existed. Unfortunately such a correlation has not been found with the results to date. However, a correlation has been observed between the number of deaths, and the average FED of the entire population of occupants (figure 3). The average FED has a smaller fractional error than the number of deaths (figure 4), so can be used to improve the accuracy. The variance reduction efficiency is a factor of 2.5 , roughly.

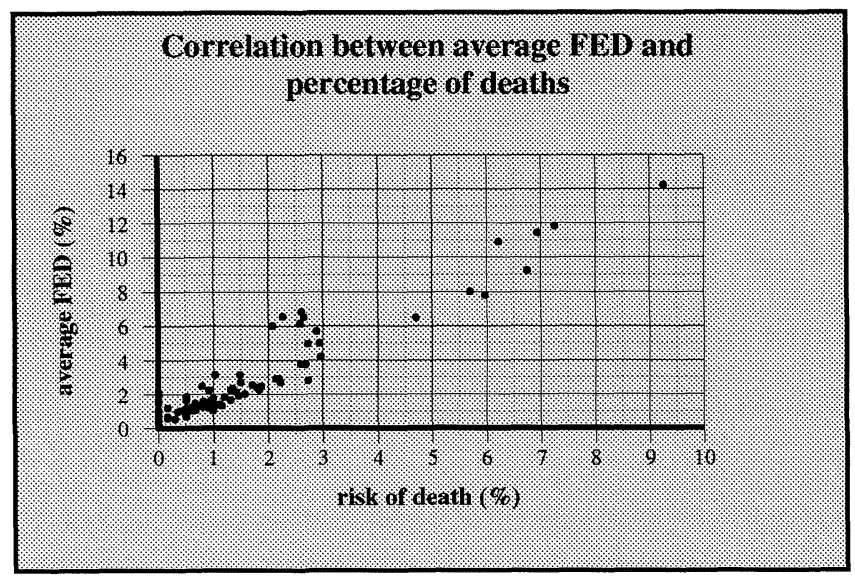

FIGURE 3. Correlation between risk of death and the average dose received by all population (NB. A lethal dose requires $\mathrm{FED}=100 \%$ )

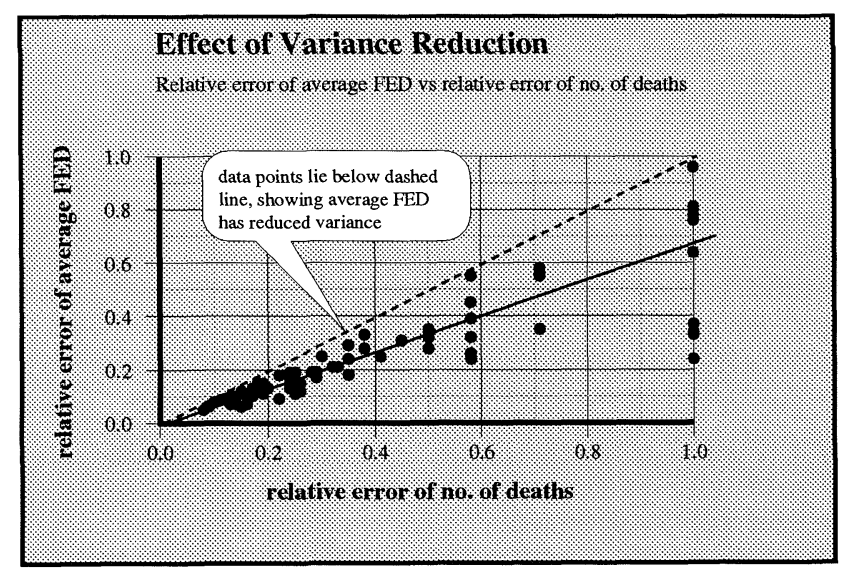

FIGURE 4. Fractional error of average FED vs fractional error of number of deaths, illustrating the variance reduction 
Another means of achieving reduced variance is by Stratified Sampling [23], which some sources call Latin Hypercube Sampling [24]. Given a probability distribution function of some variable $x$, the idea is to obtain a more representative sample by ensuring more even sampling of the variable $x$ than would happen if the values were simply chosen by uniform random numbers spanning the entire range of $x$. Instead the range is broken down into a number of strata, each of which supplies the same number of samples. The variance reduction efficiency of such methods can be impressive, of the order of the number of samples. Unfortunately, when attempted in CRISP, no variance reduction was observed. This suggests the risk does not strongly depend on any single input parameter, but rather is due to synergistic effects which make the fatal runs appear more or less uniformly distributed over the ranges of the input variables.

Importance Sampling may be used if some parts of the input distribution are known a priori to have minimal relevance. The 'attic occupied' runs (see earlier) are an example of this technique. It was found that only $\sim 7 \%$ of CRISP runs actually had the attic occupied, so $93 \%$ of the runs could be discarded without having to be simulated. The $7 \%$ of the runs that were kept took a little longer on average to complete, partly because of the time wasted initialising the runs that were rejected, partly because when the attic was occupied there were more people than normal present in the house. The average run time was increased by roughly a factor of 2 ; however by discarding $93 \%$ of the runs the variance reduction efficiency was about $0.5 / 0.07$, or roughly a factor of 7 .

\section{CONCLUSIONS}

The CRISP program has been used to perform a fire risk assessment of a two-storey domestic house, with a loft extension adding a third storey. In such a situation the Approved Document guidance advocates passive protection of the staircases. The objective of the CRISP study was to see if the use of smoke detectors could provide an equivalent level of safety.

In comparing the relative risk for occupants in the attic compared to those in the other (first floor) bedrooms, no significant differences were found. This suggests that the 'equivalent level of safety' should be by reference to the ordinary two storey house without any special measures, rather than the Approved Document's specification for protected staircase (which may be over-safe, in comparison to the two storey house). If the first floor occupants are considered 'reasonably safe' without recourse to special measures, the attic occupants are also 'reasonably safe' without special measures.

The CRISP-based analysis would suggest that active fire protection (detectors) can provide a reasonable level of safety for the attic / loft occupants, without the need for expensive passive protection.

In the simulations, the best fire protection strategy is to fit smoke alarms; one downstairs and one on the first floor landing should be sufficient. They should be interlinked to ensure they are audible. CRISP would suggest that special fire-resisting doors are not necessary, although it might be advisable to keep ordinary doors closed (the calculated effect on life risk is not clearcut, but it seems 'common sense' to do so, and should reduce property damage)

One should be very wary of extrapolating the results presented here to larger or more complex buildings.

\section{ACKNOWLEDGEMENTS}

This work was funded by the Construction Sponsorship Directorate of the Department of the Environment. 


\section{REFERENCES}

1. Department of the Environment and The Welsh Office, The Building Regulations 1991. Approved document B Fire Safety, HMSO London, 1991

2. Fraser-Mitchell,JN, An Object-Oriented Simulation (CRISP II) for Fire Risk Assessment, IAFSS Proc. 4th Int. Symp. on Fire Safety Science, p.793-804, 1994

3. Mulholland,GW, Smoke production and properties, Chapter 1-25, SFPE Handbook of Fire Protection Engineering, pub. NFPA. 1st edition (1988)

4. Tien,CL, Lee,KY \& Stretton,AJ, Radiation Heat Transfer, Chapter 1-5, SFPE Handbook of Fire Protection Engineering, pub. NFPA. 1st edition (1988)

5. Tewarson,A, Generation of heat and chemical compounds in fires, Chapter 1-13, SFPE Handbook of Fire Protection Engineering, pub. NFPA. 1st edition (1988)

6. Zukowski,EE, Development of a stratified ceiling layer in the early stages of a closed-room fire, Fire \& Materials 2(2) (1978) p.54-61

7. Heskestad,G, Virtual origins of fire plumes, Fire Safety Journal 5 (1983) p.109-114

8. Hinkley,PL, Sprinkler operation and the effect of venting: studies using a zone model, Building Research Establishment Report BR 213 (1992)

9. Beyler,CL, Major species production by solid fuels in a two-layer compartment fire environment, IAFSS Proc. 1st Int. Symp. on Fire Safety Science, p.431-440, 1985

10. Heskestad,G, Luminous heights of turbulent diffusion flames, Fire Safety Journal 5 (1983) p.103-108

11. Babrauskas, V, Burning Rates, Chapter 2-1, SFPE Handbook of Fire Protection Engineering, pub. NFPA. 1st edition (1988)

12. Spearpoint,MJ, A collection of rate of heat release data suitable for computer fire models, Building Research Establishment Note N13/93, 1993

13. Drysdale,D, An introduction to fire dynamics, p.36-37, John Wiley \& Sons (1985)

14. Sime,J, Breaux,J \& Canter,D, Human behaviour patterns in domestic and hospital fires, Building Research Establishment Occasional Paper OP59, 1994

15. Purser,DA, Toxicity assessment of combustion products, Chapter 1-14, SFPE Handbook of Fire Protection Engineering, pub. NFPA. 1st edition (1988)

16. Emmons,HW, Vent flows, Chapter 1-8, SFPE Handbook of Fire Protection Engineering, pub. NFPA. 1st edition (1988)

17. Peacock,RD, Forney,GP, Reneke,P, Portier,R \& Jones,WW, CFAST, the Consolidated model of Fire growth And Smoke Transport, National Institute of Standards and Technology, USA Technical Note 1299 p.26, 1993

18. Chandler,S, Private Communication (Analysis of Home Office Fire Statistics. 1993)

19. Leathley,B, Private Communication (Source data for fire assessment systems: Door and Window Opening Behaviour Study, Four Elements Ltd Report 2704la500ไrev01〈report2b, 1995)

20. Office of Population Censuses and Surveys, General Housing Survey 1991, series GHS no.22, HMSO, 1993

21. Fraser-Mitchell,JN, Lessons learnt during the development of CRISP2, a Monte Carlo simulation of fire risk assessment, Interflam '96 proceedings p.631-639, pub. Interscience Communications Ltd, 1996.

22. Smithies,JN, Private Communication 1996

23. Hammersley,JM \& Handscomb,DC, Monte Carlo Methods, Meuthen (1964)

24. Magnussen,SE, Frantzich, $\mathrm{H} \&$ Harada,K, Private communication (Fire safety design based on calculations: uncertainty analysis and safety verification, Report 10.10.1995, Department of Fire Safety Engineering, Lund University), 1995 